\title{
An Analysis of the Function of Energy Statistics in Enterprise's Energy Management
}

\author{
Wang Ning ${ }^{1, *}$, Jian Ming ${ }^{2}$ and Wang $\mathrm{Yu}^{3}$ \\ ${ }^{1}$ Computer Science Department, Northeast Petroleum University at Qinhuangdao, Qinhuangdao, 066004, Hebei, China; \\ ${ }^{2}$ School of Statistics, Renmin University of China, Beijing, 100872, China; ${ }^{3}$ Beijing Haidian Branch, Tarena Software \\ Technology Co., LTD. (Hangzhou), Beijing, 100098, China
}

\begin{abstract}
Energy plays a fundamental role in people's survival and development. Rational allocation and use of energy lays a foundation for an enterprise to develop steadily. Thus, enterprises must attach great importance in energy management. As one of the primary means in energy management, energy statistics is of great significance. Energy statistics focuses on accurately and comprehensively collating and collecting the various data during internal energy use. With analysis on relative statistics and information, energy statistics can truly reflect the company's energy situation. Establishing, improving and applying the energy statistics system is essentially necessary for an enterprise, for it not only improve the economic efficiency, but also reduce costs and energy consumption. This paper provides a basic overview of energy statistics, probes into the its method, and studies the role it plays in the enterprise's energy management.
\end{abstract}

Keywords: Analysis of function, energy statistics, enterprise's energy management, people's survival.

\section{INTRODUCTION}

Energy refers to those can be converted to electricity, heat, light and other resources in nature. It is the base of social development and human survival. Rational use and efficient allocation of energy is an important strategy for sustainable development of an enterprise [1-4]. Energy statistics is the most basic work in enterprise energy management, and it is also a scientific, rational basis for calculating enterprise energy efficiency as well as energy consumption [5-7]. It reflects the enterprise's energy status. Therefore, an enterprise must continue to strengthen energy statistical system, establish and improve accounting and original statistical records [8], regularly report the status of energy, and gradually form a scientific energy management, to increase energy efficiency.

\section{OVERVIEW OF ENTERPRISE ENERGY STATIS- TICS}

Energy statistics refers to the statistics of the numerical relationship, for example, economic laws, the flow of the system overall balance, and processes such as energy exploration, exploitation, production, processing, and transporting. It applies a unique measurement and scientific analysis under an integrated energy system of economic index system. The development of enterprises is inseparable from energy statistics. With professional energy statistics, an enterprise will see a great rise in its energy management, orderly management, and huge economic benefits. In the development of world economy, the demand of energy is increasing globally. Every country attaches great importance to rational energy management and increasing energy efficiency, for their great impact on economic development. Therefore, enterprises must first conduct energy statistics to not only meet the need of themselves but also for our country's socialist market economy.

\section{OBJECT AND TASK OF ENERGY STATISTICS}

\subsection{Object of Energy Statistics}

In the process of energy management of an enterprise, in order to achieve energy saving, energy statistics is inevitable, which is the most basic work of energy management $[9,10]$. The main targets of energy statistics include energy statistical reporting system, energy statistical indicator system, and measuring control, etc. The earliest form of energy statistics is ledger, with numbers its carrier. Therefore, the energy statistics work must be in strict accordance with the relevant energy statistics reporting system, to achieve standardization and rationalization. Measuring control is also particularly important. The requirements are, first of all, a reasonable measuring control mechanism for regular and standardized management; second, a precise measuring instrumentation to ensure accurate statistics and appropriate suggestions for production; third, integrity of work in combination of management and mechanism.

\subsection{Tasks of Energy Statistics}

There are two main tasks of energy statistics. First, with the national authorization and policy to ensure smooth energy statistics work, the enterprise should provide energy statistics for important basis and reference when the nation balances the energy supply and demand, and make energy 
inspection plans. Second, energy statistics not only timely collects statistics for energy status for an enterprise, finding the cause of problem, correcting and resolving the problem; but also implements national energy plans and policies. In addition, energy statistics also enhances corporate energy management, providing a strong basis for enterprise development, energy conservation, environmental protection, and energy efficiency.

\subsection{Basic Methods for Enterprise Energy Statistics}

The main purpose of energy statistics is to accurately and clearly demonstrate the processes and the flow of energy during production, and to facilitate the analysis of the energy system. Statistically, according to the process and the characteristics of the internal flow, energy can be divided into four steps, utilization, processing and conversion, distribution ad transporting, and purchasing and storage. With the energy system, the scope of energy statistics can be reasonably refined. At the same time, in accordance with the actual situation of the enterprise, energy use and relative provisions of energy use, the analysis, sorting, calculating, aggregation, and presentation will make the system more systematic and compiling, for example, form the regulation of monthly energy accounting, and vigorously conduct network statistics management. The specific steps of energy statistics are as follows:

\subsubsection{Record the Original Data of Energy Statistics}

With documents, cards and forms, we can record the data of whole process and outcome of energy activities, such as the cost of energy purchasing, the requisition time, the number and relevant statistical reports. By completing the requisition and returning sheet, it can be reflected the information of energy storage, and is decisive for obtaining the energy storage, accurately recording specific statistics for the future work.

\subsubsection{Set Energy Statistics Ledger}

According to the enterprise energy analysis and management, energy statistics report can be demonstrated in the statement and energy cumulative data book can be produced after professional accounting. Energy statistics ledger compilation is of three types. First is statistical statement ledger, which is a transitional ledger, compiled after transferred by records of original statistics. Generally it is reflected by the form and attributes of the consolidated statements. Second, energy management ledger, which calculates in accordance with business types. Third, special indicator ledger, specifically referring to a particular set of enterprise energy activity, for example, single product consumption ledger. In the meantime, companies should study and analyze the historical ledger and sum up the experience. According to the needs of energy in the company's economic activities, we collect and collate the data and demonstrate on the ledger. The problems are reflected through the data and then solved by data comparison and analysis.

\section{ENERGY STATISTICS' FUNCTION IN ENTER- PRISE'S ENERGY MANAGEMENT}

The importance of energy statistics in energy management in an enterprise is reflected on promoting implementa- tion and management of enterprise's energy statistical works, building a sound energy utilization system to record statistics of energy consumption. Energy statisticians should first fully understand the actual production process, and gradually deepen into the main sectors and working area to learn, master, and analyze the energy consumption, energy utilization for single products, and they can apply the statistical method to the analysis of relevant data and scientific research.

The energy statistics can be properly applied to the statistical graphics, for example, bar, column, pie charts and other charts can visually demonstrate the energy consumption and the information of the energy system, which facilitates the statistical analysis of the data. And with scientific analysis, we can obtain the information such as the ups and downs of energy consumption, the reasons of the changes, and the economic benefits brought by energy consumption. We can identify problems and situations in energy consumption process in an enterprise, based on which, we will find solutions for the weak parts. We can apply equipment that are low-pollution, efficient, and low-energy-consumption, to reduce the cost of production and energy consumption, and take efforts save energy and raise public awareness.

\section{ENERGY EFFICIENCY ANALYSIS}

As a comprehensive indicator, to some extent, energy efficiency reflects the condition of the equipment. It can also be an accurate reflection of the energy consumption situation in different sectors. In addition, energy efficiency can intensively show the level of competition of enterprises and the capacity of energy utilization.

Energy efficiency =
the sum of effective energy
the sum of integrated energy

in other words,

$\eta=\frac{\sum Q_{\text {Effective }}}{\sum \mathrm{Q}_{\text {Energy }}} \times 100 \%$

\section{CASE STUDIES OF ENERGY STATISTICS}

\subsection{Final Energy Statistics}

The most complex part of energy consumption in an enterprise is the final energy sector, which can be applied to one or more energy statistics ledger. According to national standards, the final energy consumption can be divided into several sections: main production, secondary production, lighting, heating, etc. This table shows the annual consumption of energy in an enterprise.

The annual final energy consumption mainly consists of auxiliary energy consumption, energy consumption in production, loss of electricity, and other energy consumption. The electricity energy loss is shown in Figs. (1 and 2).

The main types of energy consumption are diesel and electricity, which clearly reflects the use of energy. However, without figures for longitudinal comparison, we cannot specifically observe the condition, or pinpoint the potential of energy conservation. In Table $\mathbf{1}$ for each index there is a 
Table 1. Summary of energy consumption in an enterprise.

\begin{tabular}{|c|c|c|c|c|c|c|c|c|c|c|c|c|c|}
\hline \multirow[b]{2}{*}{$\begin{array}{l}\text { Energy } \\
\text { Species }\end{array}$} & \multirow[b]{2}{*}{ Measure } & \multicolumn{2}{|c|}{ Total Amount } & \multirow[b]{2}{*}{$\begin{array}{c}\text { Total } \\
\text { Consump- } \\
\text { tion }\end{array}$} & \multicolumn{6}{|c|}{ Process Energy Consumption } & \multirow[b]{2}{*}{$\begin{array}{c}\text { Energy } \\
\text { Consump- } \\
\text { tion in } \\
\text { Auxiliary } \\
\text { Production }\end{array}$} & \multirow[b]{2}{*}{ Others } & \multirow[b]{2}{*}{ Loss } \\
\hline & & Outsourcing & Production & & $\begin{array}{c}\text { Found- } \\
\text { ing }\end{array}$ & $\begin{array}{c}\text { Pull } \\
\text { Pan, } \\
\text { Rolling }\end{array}$ & $\begin{array}{c}\text { Light } \\
\text { pipe } \\
\text { polish- } \\
\text { ing }\end{array}$ & $\begin{array}{c}\text { Annealing } \\
\text { Online }\end{array}$ & $\begin{array}{c}\text { Internal } \\
\text { Grooved Copper } \\
\text { Tube Forming }\end{array}$ & $\begin{array}{c}\text { Anneal- } \\
\text { ing }\end{array}$ & & & \\
\hline Electricity & kwh & \multicolumn{2}{|c|}{5266.3} & 5249.6 & 1452.0 & 1089.2 & 22,4 & 448.0 & 162.6 & 585.5 & 845.2 & 644.1 & 17.6 \\
\hline Diesel oil & $\mathrm{t}$ & \multicolumn{2}{|c|}{14.6} & 16.7 & & & & & & & & & \\
\hline
\end{tabular}

Note: the sum of loss is actually the sum of natural loss and measurement error.

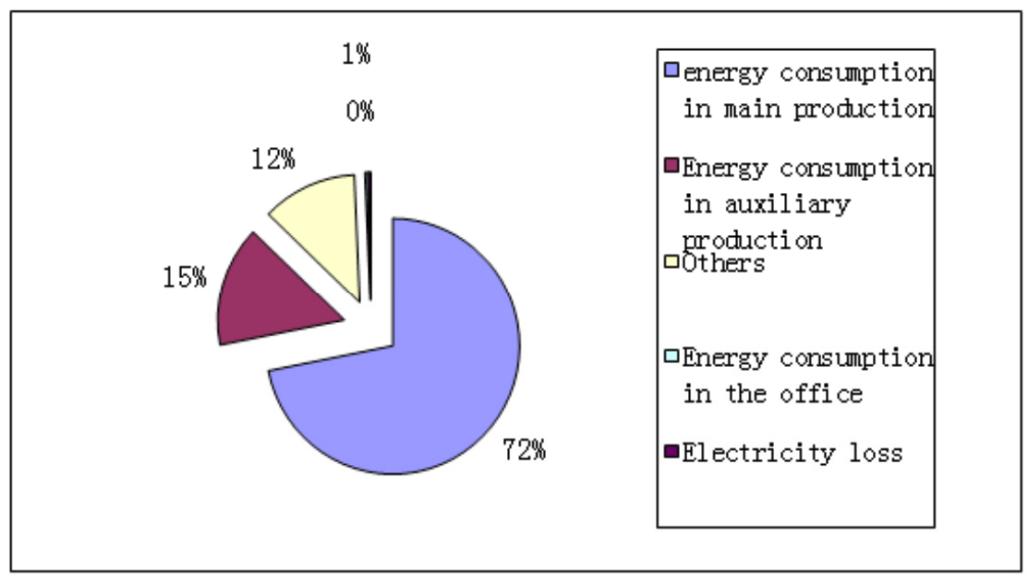

Fig. (1). Final energy consumption configuration diagram.

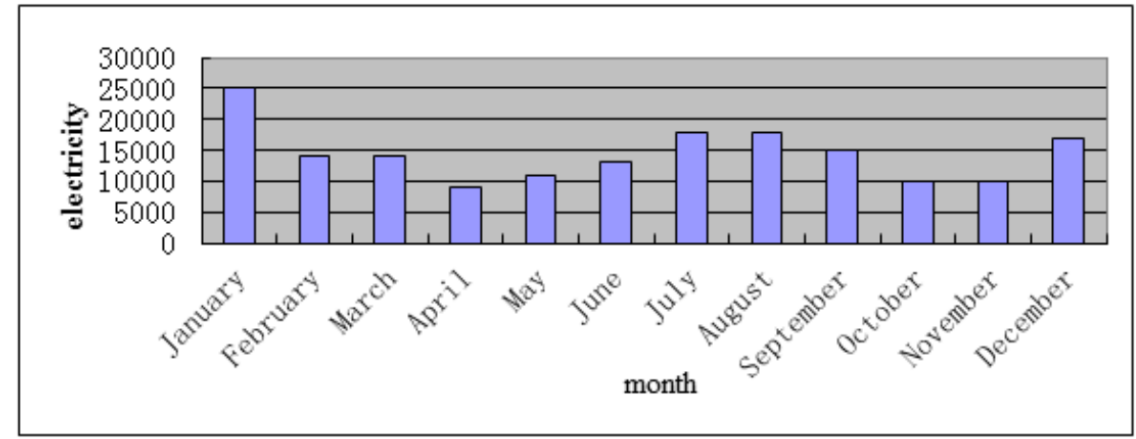

Fig. (2). Electricity histogram.

corresponding ledger, from which we can obtain much information. For example, for the statement of electricity consumption, we can get an electricity histogram.

The electricity consumption in the office only takes $0.36 \%$ of the total consumption, yet there is still potential. From the figure above, in January, July, August, and December the consumption is relatively high, due to the hot and cold weather in summer and winter, which is closely related to the use of air conditioning. Based off of this, the relevant department can establish a set of new measures to save energy from the air conditioner. For example, to strengthen the insulation, another layer of glass can be installed, or lessen the use of the air conditioner by more than half an hour, etc. More measures could be taken, for example, all the lighting installations in the office can be changed into green lighting devices, and the lighting facilities in the corridors, toilets, lounge and tea room can be changed into voice controlled energy-saving lamp. Despite their small energy consumption for each devices, after a long period of accumulation of energy saving, it will be a mass figure.

\subsection{Energy Statistics Per Unit}

There are many indicators to assess whether an enterprise is energy-saving, such as energy consumption per ten thousand yuan, overall energy consumption, energy consumption per unit of product, etc. Thus energy consumption statistics from the product is the most commonly used energy statistics method.

If the company only produces one product, it is easily to obtain the management level and energy efficiency through the statistics of the energy consumption per unit of time and the number of products. In per unit of time, quantity of energy consumption is $\mathrm{P}$, the energy consumption is $\mathrm{E}$, then the equation can be obtained as follows: 
Table 2. Comparison of rate of final products.

\begin{tabular}{|c|c|c|c|c|}
\hline \multirow{2}{*}{} & \multicolumn{2}{|c|}{ First year } & \multicolumn{2}{c|}{ Second year } \\
\cline { 2 - 5 } & Yield (t) & Energy Consumption (tce/t) & Yield (t) & Energy Consumption (tce/t) \\
\hline \hline Annealing & 20093.29 & 0.090 & 18952.23 & 0.090 \\
\hline $\begin{array}{c}\text { Internal grooved copper tube } \\
\text { forming }\end{array}$ & 19257.56 & 0.035 & 18913.21 & 0.024 \\
\hline Rate of final products & $95.3 \%$ & $/$ & $99.8 \%$ & $/$ \\
\hline
\end{tabular}

$E=E_{0}+\alpha P$

In the equation, $\alpha P$ is the energy consumption associated with the output; $\alpha$ is energy consumption of unit product, usually a constant; and $\mathrm{E}_{0}$ is energy consumption irrelevant to the product.

The energy consumption irrelevant to product is mainly from office equipment, such as lighting, air-conditioning, etc, and also the energy loss from unreasonable management and natural loss, such as solid fuels erosion, weathering, and leakage.

The main product of the enterprise is inner grooved copper tube and smooth copper tube. To know the energy consumption per unit of the inner grooved copper tube, the producing process should be understood, for example, materials in processing, and the type of consuming energy. In production process, every step consumes energy. Rolling, annealing, and founding cost nitrogen, and both producing and transporting costs diesel oil. Therefore, the total energy consumption per unit of product is:

$C=E_{0}+e+f / P$

$\mathrm{E}_{0}$ is the energy consumption irrelevant to product, $\mathrm{e}$ is the electricity consumption in producing, $f$ is the energy consumption of diesel fuel, $\mathrm{P}$ is the production output, whose measure unit is t. The weight of inner grooved copper tube is $\delta$, which is the ratio of production output $\mathrm{P}$ to the total production $\mathrm{P}_{1}$.

$\delta=\left(P / P_{1}\right) \times 100 \%$

Here we can put the data with the original data together and draw energy consumption per unit of product.

From the Table 2 above, it can be seen in the first year, the rate of final products is relatively low, leading to the rise of energy consumption of product. After analyzing, reviewing and comparing with the original data, we can draw the following conclusions: firstly, internal thread is a sophisticated molding process, causing a high rate of waste product; secondly, strengthening maintenance of the product can avoid unnecessary waste and decrease the rate of waste product; thirdly, increasing the technology and skill can decrease the rate of waste product caused by the objective factors: these are conducive for the energy management in an enterprise. As can be seen in the case above, the continuous development and improvement of energy statistics can im- prove the energy business in terms of its management to some extent, provide an accurate basis for the calculation of energy consumption.

\section{CONCLUSION}

In conclusion, energy statistics is the basis of energy management, and it is also the only source of energy data for an enterprise. Its degree of perfection and its statistics have a great impact on energy conservation and energy management for an enterprise. Energy statistics also affects the accuracy of energy-oriented works. Without reasonable statistics, an enterprise will not be able to achieve energy conservation and energy efficiency. Therefore, energy statistics plays an important role in enterprise energy management, and has a great influence on the development of the enterprise.

\section{CONFLICT OF INTEREST}

The authors confirm that this article content has no conflict of interest.

\section{ACKNOWLEDGEMENTS}

This work is supported by Heilongjiang province education scientific planning project "Research and practice of college students' entrepreneurship education base on schoolenterprise cooperation" (No. ZJC1214002), Hebei province natural science fund project "research on port supply chain management key common problems (No. G2015203378) and qinhuangdao soft science research plan project" port two-way integration research on the structure analysis and optimization of the supply chain (No. 201301B044), and Daqing city philosophy and social sciences planning research project in 2015 "research on promotion energy conservation and emissions reduction and speeding up the construction of green low-carbon transport environment in daqing city".

\section{REFERENCES}

[1] R. T. Watson, M.C. Boudreau, and A. J. Chen, "Information systems and environmentally sustainable development: energy informatics and new directions for the IS community," Management Information Systems Quarterly, vol. 34, no. 1, pp. 4, 2010.

[2] C. Shiyi, "Energy Consumption, $\mathrm{CO}_{2}$ emission and sustainable development in chinese industry," Economic Research Journal, vol. 4, pp. 1-5, 2009.

[3] Z. Ming, X. Song, M. Mingjuan, and Z. Xiaoli, "New energy bases and sustainable development in China: a review," Renewable and Sustainable Energy Reviews, vol. 20, pp. 169-185, 2013.

[4] M. Halme, and K. Maria, "Responsible innovation toward sustainable development in small and medium-sized enterprises: a re- 
source perspective," Business Strategy and the Environment, vol. 23 , no. 8, pp. 547-566, 2014.

[5] Z. Ming, X. Song, M. Mingjuan, L. Lingyun, C. Min, and W. Yuejin, "Historical review of demand side management in China: Management content, operation mode, results assessment and relative incentives," Renewable and Sustainable Energy Reviews, vol. 25, pp. 470-482, 2013.

[6] K. Vikhorev, G. Richard, and B. Neil, "An advanced energy management framework to promote energy awareness," Journal of Cleaner Production, vol. 43, pp. 103-112, 2013.

[7] Z. Liu, Y. Geng, S. Lindner, H. Zhao, T. Fujita, and D. Guan, "Embodied energy use in China's industrial sectors," Energy Policy, vol. 49, pp. 751-758, 2012.
[8] R. Kaaks, P. Ferrari, A. Ciampi, M. Plummer, and E. Riboli, "Uses and limitations of statistical accounting for random error correlations, in the validation of dietary questionnaire assessments," Public Health Nutrition, vol. 5, no. 6, pp. 969-976, 2002.

[9] G. Krieger, I. Rentschler, G. Hauske, K. Schill, and C. Zetzsche, "Object and scene analysis by saccadic eye-movements: An investigation with higher-order statistics," Spatial Vision, vol. 13, no. 2, pp. 201-214, 2000.

[10] A. Bovier, and K. Irina, "Local energy statistics in disordered systems: a proof of the local REM conjecture," Communications in Mathematical Physics, vol. 263, no. 2, pp. 513-533, 2006.

Received: June 10, 2015

Revised: July 29, 2015

Accepted: August 15, 2015

(C) Ning et al.; Licensee Bentham Open.

This is an open access article licensed under the terms of the (https://creativecommons.org/licenses/by/4.0/legalcode), which permits unrestricted, noncommercial use, distribution and reproduction in any medium, provided the work is properly cited. 